\title{
A major new alliance in Australian health care: the Australian Consensus Framework for Ethical Collaboration in the Healthcare Sector
}

\author{
Wendy Lipworth [first author and corresponding author] \\ MBBS PhD \\ Associate Professor \\ Sydney Health Ethics, University of Sydney \\ Wendy.lipworth@sydney.edu.au
}

Jane Fitzpatrick [equal first author if possible]

PhD, MB.BS, FACSEP

Associate Professor Faculty of Medicine, Dentistry and Health Sciences, University of Melbourne, Australia and Australasian College of Sport and Exercise Physicians, Melbourne, Australia

\section{Adrian Cosenza}

BCom, MCom, MBA, FAICD, FCPA, FFIN

Chief Executive Officer

Australian Orthopaedic Association

lan Kerridge

FRACP, FRCPA

Professor of Bioethics and Medicine

Sydney Health Ethics, University of Sydney

Peter Subramanian

MBBS, FRACS

Staff Vascular Surgeon, Royal Adelaide Hospital

Alison Verhoeven

BA, GDipEd, MLitt, MBA (Dist), GAICD

Chief Executive

Australian Healthcare and Hospitals Association

Leanne Wells

BA (Comms), GradDipBusMgt, MAIM, MAICD

Chief Executive Officer

Consumers Health Forum of Australia

This is the author manuscript accepted for publication and has undergone full peer review but has not been through the copyediting, typesetting, pagination and proofreading process, which may lead to differences between this version and the Version of Record. Please cite this article as doi: 10.1111/imj.14861

This article is protected by copyright. All rights reserved. 
Abstract:

The "Australian Consensus Framework for Ethical Collaboration in the Healthcare Sector" (ACF) is an Australian initiative aimed at countering dysfunction and growing mistrust in the health sector through the development of a cross-sectoral consensus framework. The development of this framework arose from Australia's involvement in the Asia Pacific Economic Cooperative (APEC) and has since become the largest of its kind internationally, with over 70 signatories representing professional bodies, industry organisations, hospital and health services associations, regulators, and patient and advocacy groups. In this article, we describe and critique the framework and outline its implementation.

By global standards, the Australian health system is well organised and highly effective, as evident in positive health outcomes, a comprehensive system for health education, a strong health workforce, a productive health and biomedical research sector, and robust processes for the regulation and subsidisation of health technologies. Nonetheless, the system is facing a number of persisting and newly emerging challenges resulting from the fragmentation and complexity of healthcare delivery, ${ }^{\text {e.g. }}{ }^{1}$ growing costs of health technologies and services, ${ }^{\text {e.g.2 }}$ chronically under-served populations, e.g.3 demographic changes, ${ }^{\text {e.g.4 }}$ an increase in complex, chronic diseases, ${ }^{\text {e.g.5 }}$ and increasing stresses on the workforce. e.g. ${ }^{6}$ In addition, like health systems internationally, the reputation of the Australian system is impacted upon by publicity surrounding episodes of research ${ }^{\text {e.g.7 }}$, professionale.g.8 and corporate ${ }^{\text {e.g.9 }}$ misconduct, and failure on the part of health services ${ }^{\text {e.g.10 }}$ and regulatory bodies ${ }^{\text {e.g.11 }}$ to protect patients from harm or exploitation.

The evolving COVID-19 pandemic is quickly revealing both the strengths and weaknesses of the Australian health sector. The speed with which public resources have been allocated to healthcare ${ }^{12}$ and public-private alliances have been formed, ${ }^{13}$ and the obvious commitment of health professionals to caring for patients with COVID-19 ${ }^{14}$ have no doubt been a source of public confidence and pride. But problems such as lack of personal protective equipment (PPE) for healthcare workers, ${ }^{15}$ breakdowns of basic quarantine measures ${ }^{16}$ and variation in the implementation of public health advice across different jurisdictions ${ }^{17}$ have reignited public concerns about the organisations responsible for the design and delivery of healthcare. ${ }^{18-23}$

COVID-19 has also highlighted the critical necessity of collaboration for social benefit in the health sector. This is because an effective response to COVID 19 requires that testing equipment is manufactured and delivered, PPE is available to all who need it, hospital facilities including intensive care beds are available in both the public and private sector, 
there is an adequate healthcare workforce, research into vaccines and therapeutics are fasttracked and supported, and public health measures are evidence-based and enforced. All of these components of the response to COVID-19 require extensive planning and coordination; they also require that the organisations that make up the health care sector are perceived to be legitimate (or to have so-called "social licence" ${ }^{24}$ ).

Importantly, the causes of loss of trust and social licence in health systems are morally and politically complex, and involve organisations spanning public, private and non-government sectors. Their solution therefore relies on organisations collaborating for common good and mutual benefit. This, however, raises its own challenges because organisations can have widely divergent interests. Here we describe an Australian initiative to counter the growing dysfunction and mistrust in the health sector through the development of a cross-sectoral collaboration-the Australian Ethical Health Alliance (AEHA).

The development of this collaboration arose from Australia's involvement in the Asia Pacific Economic Cooperative (APEC). APEC is a multilateral economic and trade forum established in 1989 to leverage the growing interdependence of the Asia-Pacific region. Its 21 members, which include the Unites States, Russia, China, Australia, Canada, Indonesia, Japan and Singapore, aim to promote sustainable economic growth and prosperity and accelerate regional economic integration.

Since 2010, the APEC Business Ethics for APEC Small and Medium Sized Enterprises (SMEs) Initiative has driven the development of several "consensus frameworks" for ethical collaboration within healthcare sectors. Following the development of frameworks in Canada, Vietnam and Peru, the development of an Australian framework began in 2017. Australia's approach quickly diverged from that of other countries based on the recognition that consensus frameworks should encompass the whole health "ecosystem' (beyond the business sector) and include clinical, consumer, health service and regulatory organisations alongside industry and government.

\section{The Australian Consensus Framework for Ethical Collaboration in the Healthcare Sector}

Australia's consensus framework, which has since become known as the "Australian Consensus Framework for Ethical Collaboration in the Healthcare Sector" (ACF) [Boxes 1 and 2] was launched in 2018 following endorsement by the Federal Government. The ACF consists of a set of guiding principles, to which organisations can become signatories, and which are designed to:

- $\quad$ Promote collaboration and interaction among healthcare sector organisations and those who work within them that benefits patients, consumers, communities, populations, healthcare systems and the healthcare sector. 
- $\quad$ Encourage better dialogue, trust and respect between and amongst organisations in the healthcare sector.

- Enhance the integrity and trustworthiness of organisations in the healthcare sector.

- $\quad$ Promote public confidence and trust in healthcare sector organisations by demonstrating a shared commitment to integrity and ethics.

The decision was made to focus the framework on mid-level guiding principles rather than on rules or on a single ethical theory. While principle-based approaches to ethics have been criticised for being insufficiently grounded in moral theory, non-generalisable from context to context, and insufficiently action-guiding, it was felt that a principle-based approach would provide the best means of articulating the values necessary for building trust and collaboration in the healthcare sector. This is because principles arise from commonly shared values and so facilitate communication face of disagreement and difference. Principles are also recognised by a wide range of stakeholders as having moral force, and can usefully guide action. ${ }^{25,} 26$

The selection of principles took into account the consensus frameworks that had been developed by other countries and other APEC codes of ethics such as those guiding business ethics in the pharmaceutical sector. ${ }^{27}$ It also took into account normative principles that have been articulated in medical ethics ${ }^{25}$ and public health ethics ${ }^{28}$, as well as within influential codes of ethics, including those guiding global public health, bioethics ${ }^{29}$ research, ${ }^{30}$ medical practice, ${ }^{31}$ public administation ${ }^{32}$ and global business. ${ }^{33}$ The selection of principles also drew heavily on philosophical ideas about procedural justice and fairness, particularly those of John Rawls as articulated in Daniels and Sabin's "accountability for reasonableness" (A4R) framework. ${ }^{34}$ This framework articulates principles that must be satisfied in order for decision-making and policy development to be perceived as legitimate, even by those who are adversely affected by their outcomes.

The principles were initially developed by a writing group, which included two bioethicists and representatives from industry, professional, regulatory and consumer organisations. The principles were then refined iteratively by the broader group of 50 framework signatories including consumers, health care professionals, hospitals, businesses and government representatives. This broad representation ensured that the framework would have legitimacy in the sector, and that it would reflect concern for individuals, communities and organisations in industry, government and NGO sectors. After several rounds of consultation, 15 principles were articulated.

To assist with their implementation, the principles were divided into "substantive principles" [Box 1]-which articulate the kinds of "external" goods, that organisations should strive for-and "procedural principles" [Box 2]-which articulate how organisations 
should act in in developing policy, collaborating and communicating with the public and other stakeholders.

Although the principles were initially focused on mechanisms of collaboration among organisations within the health sector, they are in fact much broader than this, and can be thought of as a set of considerations that can assist organisations to enhance their real and perceived trustworthiness by showing that they are committed to the right goals (substantive principles) and to the right ways of achieving these goals (procedural principles).

\section{Box 1: Substantive principles}

Those working together and/or making collaborative judgements and decisions should give due consideration to:

- $\quad$ Benefit and welfare: Acting in ways that advance the health, wellbeing and interests of patients, consumers, communities, populations, healthcare systems and the healthcare sector, and that avoid or minimise harm.

- Justice: Fair distribution of access, opportunities, and privileges, with an emphasis on addressing socio-political and economic inequality. Justice also refers to fairness in the processes that allocate resources and resolve disputes

- $\quad$ Respect for patients, consumers, communities, colleagues and organisations: All interactions and activities are respectful of the dignity, worth, rights, beliefs, values, preferences, customs and cultural heritage of all involved.

- Solidarity: A collective commitment to sharing costs and benefits for the good of a group, community, nation or global population.

- $\quad$ Effectiveness, efficiency, safety, sustainability: Continuous commitment to improving outcomes in healthcare through promotion of responsible innovation, generation and utilisation of evidence, economic cooperation, reduction of waste, and productive utilisation of limited resources.

\section{Box 2: Procedural principles}

Collaborations and interactions should be characterised by:

- Honesty: Those engaged in collaborations are truthful in all their interactions.

- Integrity: Those engaged in collaborations are alert to competing and conflicting personal, professional and organisational interests and to the management of bias.

- $\quad$ Reflexivity: There is ongoing critical reflection on the values, principles and evidence underpinning collaborative judgments and actions.

- $\quad$ Transparency: The processes of collaboration, and the values, principles and evidence upon which decisions are made, are open to scrutiny.

- Inclusiveness and shared understanding: All relevant stakeholders should participate in collaborations in order to learn from one another and work together respectfully to generate mutually agreed outcomes.

- $\quad$ Responsibility and accountability: Those involved in collaborative processes take responsibility for, are able to explain, and are accountable for, their actions and decisions.

- $\quad$ Reasonableness: Those involved in collaborations act, and make decisions, on the basis of rationales that are widely accepted as relevant and fair.

- $\quad$ Testability: The judgments and decisions made by those engaging in collaboration are open to 
independent verification and revision.

- $\quad$ Revisability: There are procedures in place for appeals and for revising collaborative judgments and decisions in the light of challenges to them.

- $\quad$ Oversight: There are mechanisms in place to ensure that the principles described above are given due consideration.

The framework was formally launched in Tokyo on 20 July 2018. At the time of its launch, the framework had been endorsed by 55 organisations representing industry, government, the professions, consumer groups, regulatory bodies and health providers. In signing up to the framework, these organisations commitment to work to align their own policies and processes with the consensus principles and take the principles into account in their activities including education and training, research, advocacy, purchasing and resource allocation, and policymaking. By early 2019 the number of signatories had risen to over 70 organisations (listed below), making the ACF the largest of its type in the world. At this point, the Australian Ethical Health Alliance (AEHA) was established to support the implementation of the ACF. The AEHA has since developed an implementation program that provides organisations and signatories with the resources that they need to develop and modify their policies and processes in alignment with the ACF. At present, it is envisaged that signatories to the ACF will report regularly to the AEHA and share their experiences and resources on a newly established website: www.ethicalhealth.org.au.

\section{What can be achieved by cross-sectoral ethics initiatives?}

Although the ACF has attracted unprecedented support from across the Australian health sector, it is open to different types of critique. In addition to the limitations of principlebased ethics described earlier, there are serious questions about whether frameworks of this type have "real world impacts". For the reality is that ethical statements of any kind are not enforceable, and there is no guarantee that organisations that become members of AEHA and sign up to the ACF will institute any substantive changes in organisational behaviour. Indeed, agreement on general ethical principles may obscure more substantive value conflicts and, in some cases, be used as "tokens of legitimacy"35 or as "ethics theatre ${ }^{\prime 26}$ to mask wrongdoing at an organisational or systemic level. In this regard, it is noteworthy that organisations are beginning to express an interest in membership whose values do not appear to align with the ACF, and the organisation is now grappling with how to assess and monitor the commitment of organisations to acting in accordance with the principles outlined in the ACF.

Another, more practical, challenge associated with statements such as the ACF is that they need to be aligned with existing regulations, codes and policies and into activities involving organisational members. This challenge (which may have discouraged some organisations from signing up to the ACF) may add to the complexity of organisational governance and 
place extra demands on those responsible for such governance. Finally, even if codes are aligned with organisational policies and procedures, they are unlikely to translate into changes in attitudes or actions unless they are scaffolded by ethical leadership and by a culture that embeds ethics at all levels of the organisation. ${ }^{36}$

Despite these challenges and limitations, the ACF has the potential to strengthen the rigour and impact on behaviour of organisational codes, guidelines and policies-particularly those that currently have limited ethical infrastructure. The ACF also provides a common language and "network of concepts" 26:369 that can form the basis of organisational activities involving their members (e.g. ethics education initiatives) and discussion among organisations with otherwise disconnected ways of thinking and communicating. Perhaps most importantly, the ACF may engender explicit discussion of issues that are often avoided-such as those centred on what organisations with political, commercial and professional agendas owe to the communities they are intended to serve. In so doing, the ACF might help to enhance the perceived trustworthiness and social licence of organisations within the healthcare sector. At a time when ethical issues regarding public and private resource allocation, the duties owed by and to the health workforce, fast-tracking of research, and tensions between "economic" and "health"-related social goods are coming to the fore the weight given to ethical principles by the existence of the ACF could foment further reflection and encourage reform.

\section{Acknowledgements}

We would like to thank Ian Burgess, Chief Executive Officer, Medical Technology Association of Australia for his review of the manuscript.

\section{Author contributions}

All authors contributed to the development of the ACF. WL and IK wrote the first draft of this article. All authors were involved in critically revising and editing it. All authors have approved the submitted version and agree to be accountable for all aspects of the work.

\section{Organisations that have become signatories to the ACF}

Arthroplasty Society of Australia

Assistive Technology Suppliers Australia

Audiology Australia

Australasian College of Cosmetic Surgery

Australasian College of Dermatologists

Australasian College of Health Service Management

Australasian College of Phlebology

Australasian College of Sport and Exercise Physicians

Australasian Leukemia and Lymphoma Group

Australasian Sarcoma Study Group 
Australasian Sleep Association

Australian and New Zealand Association of Oral and Maxillofacial Surgeons

Australian and New Zealand College of Anaesthetists

Australian and New Zealand College of Paramedicine

Australian and New Zealand Melanoma Trials Group

Australian and New Zealand Sarcoma Association

Australian and New Zealand Society for Geriatric Medicine

Australian and New Zealand Society for Vascular Surgery

Australian and New Zealand Society of Cardiac and Thoracic Surgeons

Australian and New Zealand Urogenital and Prostate Cancer Trials Group Ltd

Australian College of Emergency Medicine

Australian College of Nursing

Australian Dental Association

Australian Hand Surgery Society

Australian Healthcare and Hospitals Association

Australian Knee Society

Australian Orthopaedic Association

Australian Orthopaedic Association Medical Legal Society

Australian Orthopaedic Foot and Ankle Society

Australian Orthopaedic Trauma Society

Australian Paediatric Orthopaedic Society

Australian Pharmacy Council

Australian Private Hospitals Association

Australian Society of Anaesthetists

Australian Society of Clinical Immunology and Allergy

Australian Society of Ophthalmologists

Australian Society of Otolaryngology Head and Neck Surgery

Australian Society of Plastic Surgeons

Australian Traditional Medicine Society

Breast Cancer Trials

BUPA

Complementary Medicines Australia

Consumer Healthcare Products

Consumers Health Forum of Australia

Cosmetic Physicians College of Australasia

Day Hospitals Australia

Gastroenterlogical Society of Australia

Medical Technology Association of Australia

Medicines Australia

Musculoskeletal Australia

National Prescribing Service (NPS) Medicinewise

This article is protected by copyright. All rights reserved. 
National Rural Health Alliance

Neurological Society of Australia

Painaustralia

Praxis Australia

Private Healthcare Australia

Royal Australasian College of Dental Surgeons

Royal Australasian College of Physicians

Royal Australasian College of Surgeons

Royal Australian and New Zealand College of Obstetricians and Gynaecologists

Royal Australian and New Zealand College of Ophthalmologists

Royal Australian and New Zealand College of Psychiatrists

Royal Australian College of General Practitioners

Royal College of Pathologists of Australasia

Shoulder and Elbow Society of Australia

Skin Cancer College

Society of Hospital Pharmacists of Australia

Spine Society of Australia

The Thoracic Society of Australia and New Zealand

Universities Australia

Urological Society of Australia and New Zealand

1 Hall J. Australian health care-the challenge of reform in a fragmented system. $N$ Engl J Med 2015; 373: 493-497.

2 Goldsbury DE, Yap S, Weber MF, et al. Health services costs for cancer care in Australia: Estimates from the 45 and Up Study. PLOS ONE 2018; 13: e0201552.

3 Meiklejohn JA, Adams J, Valery PC, et al. Indigenous cancer care in Queensland, Australia: Health professionals' framing of "difference". Australian Journal of Cancer Nursing 2015; 16: 4-12.

4 Dent E, Hoon E, Karnon J, et al. Frailty and health service use in rural South Australia. Arch Gerontol Geriatr 2016; 62: 53-58.

5 Harrison C, Henderson J, Miller G, et al. The prevalence of complex multimorbidity in Australia. Aust N Z J Public Health 2016; 40: 239-244.

6 Crawford-Williams F, Goodwin B, March S, et al. Challenges and opportunities for cancer care in regional Australia: The health professional's perspective. J Glob Oncol 2018; 4: $227 s$.

$7 \quad$ Breen K. Research misconduct: time for a re-think? Internal Med J 2016; 46: 728733.

8 Wardle JL, Sibbritt D, Broom A, et al. Is health practitioner regulation keeping pace with the changing practitioner and health-care landscape? An Australian perspective. Front Public Health 2016; 4: 91.

This article is protected by copyright. All rights reserved. 
9 Flynn K. Financial fraud in the private health insurance sector in Australia. J Financ Crime 2015; 23: 143-158.

10 Roughead EE, Semple SJ, Rosenfeld E. The extent of medication errors and adverse drug reactions throughout the patient journey in acute care in Australia. Int J Evid Based Healthc 2016; 14: 113-122.

11 Byard RW, Musgrave I, Maker G, et al. What risks do herbal products pose to the Australian community? Med J Aust 2017; 206: 86-90.

12 Prime Minister of Australia. 2.4 Billion Health Plan to Fight COVID-19. 2020. https://www.pm.gov.au/media/24-billion-health-plan-fight-covid-19. (Accessed April 14 2020)

13 Department of Health. Australian Government partnership with private health sector secures 30,000 hospital beds and 105,000 nurses and staff, to help fight COVID-19 pandemic. 2020. https://www.health.gov.au/ministers/the-hon-greg-hunt$\mathrm{mp} /$ media/australian-government-partnership-with-private-health-sector-secures-30000hospital-beds-and-105000-nurses-and-staff-to-help-fight-covid-19-pandemic. (Accessed April 14 2020)

14 Department of Health. Training to help nurses re-enter the health workforce. 2020. https://www.health.gov.au/ministers/the-hon-greg-hunt- $\mathrm{mp} / \mathrm{media} /$ training-to-helpnurses-re-enter-the-health-workforce. (Accessed April 14 2020)

$15 \quad A B C$ News. Coronavirus treatment doctors report trauma, threats over lack of PPE in hospitals. 2020. https://www.abc.net.au/news/2020-04-09/coronavirus-doctors-traumaas-ppe-equipment-sharing-re-use/12136692. (Accessed April 14 2020)

$16 \quad A B C$ News. Coronavirus investigation into Ruby Princess will take five months, NSW Premier says. 2020. https://www.abc.net.au/news/2020-04-14/coronavirus-investigationinto-ruby-princess-will-take-months/12146398. (Accessed April 14 2020)

$17 \quad A B C$ News. Coronavirus uncertainty driven by inconsistent public health advice, AMA says. 2020. https://www.abc.net.au/news/2020-03-06/coronavirus-mixed-messagingdriving-confusion-ama-warns/12027898. (Accessed April 14 2020)

18 Edelman. 2018 Edelman Trust Barometer Healthcare: Global. 2018. https://www.edelman.com/sites/g/files/aatuss191/files/201810/Edelman Trust Barometer Global Healthcare 2018.pdf. (Accessed June 19 2019) 19 Ward PR, Rokkas P, Cenko C, et al. A qualitative study of patient (dis) trust in public and private hospitals: the importance of choice and pragmatic acceptance for trust considerations in South Australia. BMC Health Serv Res 2015; 15: 297.

20 Meyer SB. Investigations of trust in public and private healthcare in Australia: a qualitative study of patients with heart disease. J Sociol 2015; 51: 221-235.

21 Critchley CR. Public opinion and trust in scientists: The role of the research context, and the perceived motivation of stem cell researchers. Public Underst Sci 2008; 17: 309327. 
22 Delany-Crowe T, Popay J, Lawless A, et al. The role of trust in joined-up government activities: Experiences from Health in All Policies in South Australia. Aust J Publ Admin 2019; 78: $172-190$.

23 Monk D. Improving transparency in the pharmaceutical industry. Australian Prescriber 2016; 39: 110.

24 Raman S, Mohr A. A social licence for science: capturing the public or co-constructing research? Soc Epistemol 2014; 28: 258-276.

25 Beauchamp T, Childress J. Principles of Biomedical Ethics. 6th Edition ed. New York: Oxford University Press, 2009.

26 Levitt M, Zwart H. Bioethics: An export product? Reflections on hands-on involvement in exploring the "external" validity of international bioethical declarations. $J$ Bioeth Inq 2009; 6: 367-377.

27 Asia-Pacific Economic Cooperation. The Mexico City Principles for Voluntary Codes of Business Ethics in the Biopharmaceutical Sector. 2001. http://mcprinciples.apec.org/view.asp?ccid=451. (Accessed June 20 2019)

28 Childress JF, Faden RR, Gaare RD, et al. Public health ethics: mapping the terrain. $J$ Law Med Ethics 2002; 30: 170-178.

29 UNESCO. Universal Declaration on Bioethics and Human Rights. 2005.

http://portal.unesco.org/en/ev.phpURL ID=31058\&URL DO=DO TOPIC\&URL SECTION=201.html. (Accessed June 20 2019)

30 National Commission for the Protection of Human Subjects in Biomedical and Behavioral Research. The Belmont Report: Ethical Principles and Guidelines for the Protection of Human Subjects of Research. 1979. https://www.hhs.gov/ohrp/regulationsand-policy/belmont-report/index.html. (Accessed July 10 2019)

31 American Medical Association. AMA Code of Medical Ethics. https://www.amaassn.org/delivering-care/ethics/code-medical-ethics-overview. (Accessed June 20 2019) 32 American Society for Public Administration. Code of Ethics. https://www.aspanet.org/ASPA/Code-of-Ethics/Code-of-Ethics.aspx. (Accessed June 20 2019)

33 Scherer AG, Smid M. The downward spiral and the US model business principlesWhy MNEs should take responsibility for the improvement of world-wide social and environmental conditions. Manag Int Rev 2000; 351-371.

34 Daniels N, Sabin J. Setting limits fairly: can we learn to share medical resources?: Oxford University Press, 2002.

35 Sipp D, Caulfield T, Kaye J, et al. Marketing of unproven stem cell-based interventions: A call to action. Sci Transl Med 2017; 9: pii: eaag0426.

36 Webley S, Werner A. Corporate codes of ethics: Necessary but not sufficient. Business Ethics: A European Review 2008; 17: 405-415. 


\title{
A major new alliance in Australian health care: the Australian Consensus Framework for Ethical Collaboration in the Healthcare Sector
}

\author{
Wendy Lipworth [first author and corresponding author] \\ MBBS PhD \\ Associate Professor \\ Sydney Health Ethics, University of Sydney \\ Wendy.lipworth@sydney.edu.au \\ Jane Fitzpatrick [equal first author if possible] \\ PhD, MB.BS, FACSEP \\ Associate Professor Faculty of Medicine, Dentistry and Health Sciences, University of \\ Melbourne, Australia and Australasian College of Sport and Exercise Physicians, Melbourne, \\ Australia \\ Adrian Cosenza \\ BCom, MCom, MBA, FAICD, FCPA, FFIN \\ Chief Executive Officer \\ Australian Orthopaedic Association \\ lan Kerridge \\ FRACP, FRCPA \\ Professor of Bioethics and Medicine \\ Sydney Health Ethics, University of Sydney \\ Peter Subramanian \\ MBBS, FRACS \\ Staff Vascular Surgeon, Royal Adelaide Hospital \\ Alison Verhoeven \\ BA, GDipEd, MLitt, MBA (Dist), GAICD \\ Chief Executive \\ Australian Healthcare and Hospitals Association \\ Leanne Wells \\ BA (Comms), GradDipBusMgt, MAIM, MAICD \\ Chief Executive Officer \\ Consumers Health Forum of Australia
}




\section{University Library}

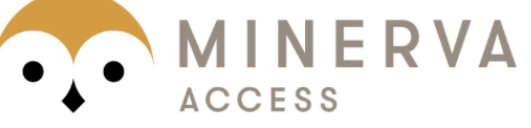

A gateway to Melbourne's research publications

Minerva Access is the Institutional Repository of The University of Melbourne

Author/s:

Lipworth, W;Fitzpatrick, J;Cosenza, A;Kerridge, I;Subramanian, P;Verhoeven, A;Wells, L

Title:

A major new alliance in Australian healthcare: the Australian consensus framework for ethical collaboration in the healthcare sector

Date:

2020-06-01

\section{Citation:}

Lipworth, W., Fitzpatrick, J., Cosenza, A., Kerridge, I., Subramanian, P., Verhoeven, A. \& Wells, L. (2020). A major new alliance in Australian healthcare: the Australian consensus framework for ethical collaboration in the healthcare sector. INTERNAL MEDICINE JOURNAL, 50 (6), pp.679-684. https://doi.org/10.1111/imj.14861.

Persistent Link:

http://hdl.handle.net/11343/275801 